\title{
Endoscopic retrieval of a scalpel from the terminal ileum
}

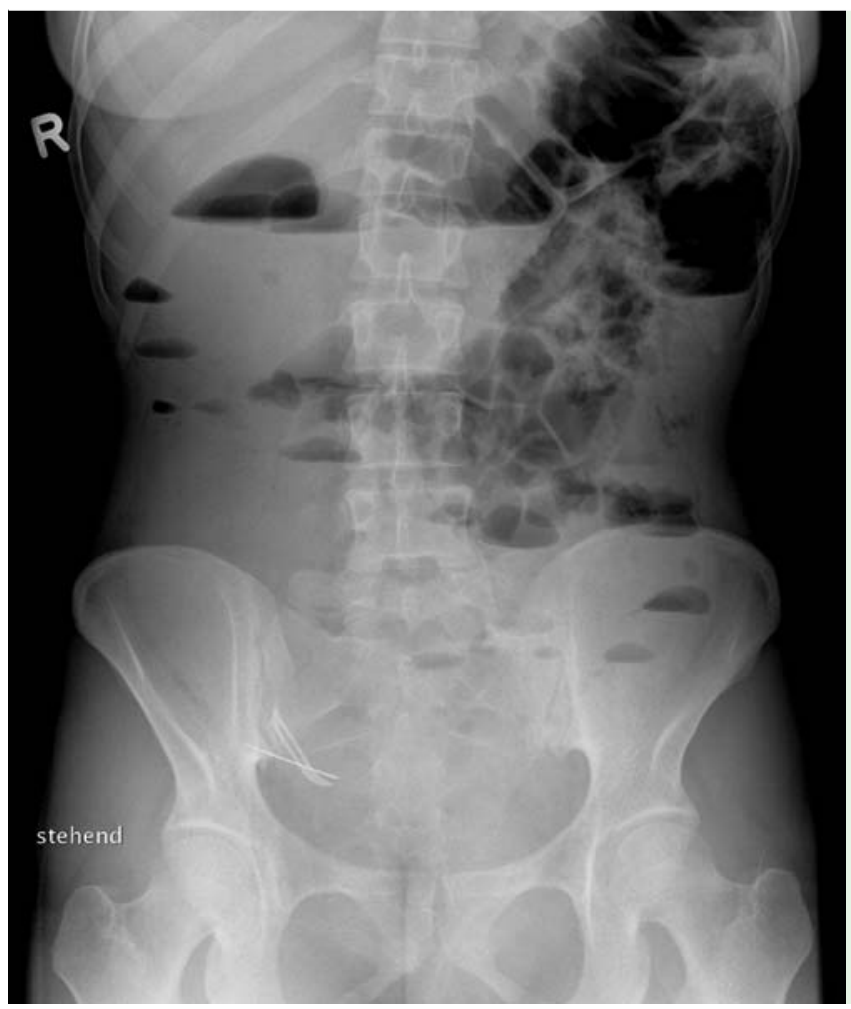

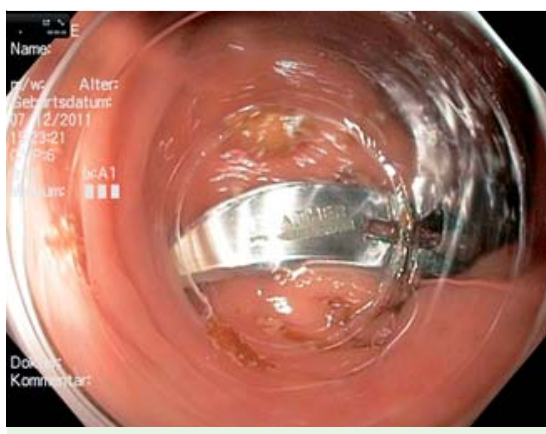

Fig. 2 At the time of the first endoscopy both scalpel blades were already inside the cecal pole.
A 26-year-old female patient was referred to us from the psychiatric ward. The patient, who was known to have a borderline personality disorder, had swallowed two scalpels.

An abdominal radiograph showed two adjacent, radiopaque foreign bodies in the shape of scalpel blades in the right mid abdomen. We decided at this stage on a conservative treatment approach conducted by clinical observation in the psychiatric ward.
Fig. 1 Abdominal radiograph in the erect position on the 3 rd day after admission shows distal subileus of the small intestine with multiple small-intestinal air-fluid levels without dilation of the small intestine and without free intra-abdominal gas. The scalpels have obviously not been moved into the cecum.

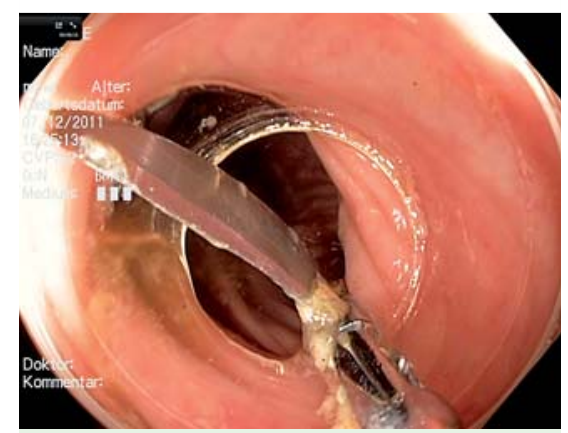

Fig. 3 Using grasping forceps we were able to take hold of one of the blades at its sharp end. It was pulled back into the mucosectomy cap so that the sharp end was completely covered.
We decided to try endoscopic removal of the foreign bodies. After oral intestinal lavage, an ileocolonoscopy using a standard colonoscope was performed with the patient lying on her left side. In addition, we used a mucosectomy attachment cap (16 mm diameter, effective asymmetric cap length 9-14mm). The two scalpel blades were inside the cecal pole ( Fig.2). Using grasping forceps we were able to take hold of one of the blades at its sharp end. It was pulled back into the mucosectomy cap so that the sharp end was completely covered ( Fig.3, Video 1). The second blade was retrieved in the same way. A final thorough colonoscopy with a deep intubation into the terminal ileum did not show any signs of mucosal injuries or irritation.

The patient underwent normal observation in the recovery ward and was then transferred back to the psychiatric ward without any complaints.

Endoscopy_UCTN_Code_TTT_1AQ_2AH

Competing interests: None

\section{Video 1}

Using grasping forceps we were able to take hold of one of the blades at its sharp end. It was pulled back into the mucosectomy cap so that the sharp end was completely covered.

\section{Merkel, D. Wiens, K.-M. Derwahl}

St. Hedwig-Krankenhaus, Berlin, Germany

Bibliography

Dol http://dx.doi.org/

10.1055/s-0032-1309862

Endoscopy 2012; 44: E279

(c) Georg Thieme Verlag KG

Stuttgart · New York

ISSN 0013-726X

On the third day, the patient complained of diffuse pain of increasing severity in the abdomen and lack of appetite without vomiting. Clinical examination revealed moderate diffuse peritonitis accompanied by reduced and, in part, high-pitched bowl sounds. An abdominal radiograph with the patient standing revealed distal subileus of the small intestine with multiple smallintestinal air-fluid levels without dilation of the small intestine and without free intra-abdominal gas ( $\bullet$ Fig. 1).
Corresponding author

\section{Merkel, MD}

St. Hedwig-Krankenhaus

Innere Abteilung

Grosse Hamburger Str. 5-11

10115 Berlin

Germany

Fax: +49-30-23112324

merkel@gmx.com 